\title{
Continuous and consistent land use/cover change estimates using socio-ecological data
}

\author{
Michael Marshall ${ }^{1}$, Michael Norton-Griffiths ${ }^{1}$, Harvey Herr ${ }^{1}$, Richard Lamprey ${ }^{2}$, Justin Sheffield ${ }^{3}$, \\ Tor Vagen ${ }^{1}$, and Joseph Okotto-Okotto ${ }^{4}$ \\ ${ }^{1}$ Climate Research Unit, World Agroforestry Centre, United Nations Ave, Gigiri, \\ P.O. Box 30677-00100, Nairobi, Kenya \\ ${ }^{2}$ Fauna \& Flora International, The David Attenborough Building, Pembroke St, \\ Cambridge, CB2 3QZ, UK \\ ${ }^{3}$ Department of Civil and Environmental Engineering, Princeton University, \\ Princeton, NJ 08544, USA \\ ${ }^{4}$ Lake Basin Development Authority, P.O. Box 1516-40100, Kisumu, Kenya \\ Correspondence to: Michael Marshall (m.marshall@cgiar.org)
}

Received: 11 August 2016 - Discussion started: 9 September 2016

Revised: 10 December 2016 - Accepted: 4 January 2017 - Published: 8 February 2017

\begin{abstract}
A growing body of research shows the importance of land use/cover change (LULCC) on modifying the Earth system. Land surface models are used to stimulate land-atmosphere dynamics at the macroscale, but model bias and uncertainty remain that need to be addressed before the importance of LULCC is fully realized. In this study, we propose a method of improving LULCC estimates for land surface modeling exercises. The method is driven by projectable socio-ecological geospatial predictors available seamlessly across sub-Saharan Africa and yielded continuous (annual) estimates of LULCC at $5 \mathrm{~km} \times 5 \mathrm{~km}$ spatial resolution. The method was developed with 2252 sample area frames of $5 \mathrm{~km} \times 5 \mathrm{~km}$ consisting of the proportion of several land cover types in Kenya over multiple years. Forty-three socio-ecological predictors were evaluated for model development. Machine learning was used for data reduction, and simple (functional) relationships defined by generalized additive models were constructed on a subset of the highest-ranked predictors $(p \leq 10)$ to estimate LULCC. The predictors explained 62 and $65 \%$ of the variance in the proportion of agriculture and natural vegetation, respectively, but were less successful at estimating more descriptive land cover types. In each case, population density on an annual basis was the highest-ranked predictor. The approach was compared to a commonly used remote sensing classification procedure, given the wide use of such techniques for macroscale LULCC detection, and outperformed it for each land cover type. The approach was used to demonstrate significant trends in expanding (declining) agricultural (natural vegetation) land cover in Kenya from 1983 to 2012, with the largest increases (declines) occurring in densely populated high agricultural production zones. Future work should address the improvement (development) of existing (new) geospatial predictors and issues of model scalability and transferability.
\end{abstract}




\section{Introduction}

Land use/cover change (LULCC) is an important concern for global environmental sustainability because it can adversely affect surface albedo and heating (Davin and de NobletDucoudré, 2010), evapotranspiration and other components of the hydrologic cycle (Sterling et al., 2013), local to regional climate with the coupling or indirect recycling of surface moisture (Makarieva et al., 2013), global climate via carbon and other greenhouse gas emissions (Anderson-Teixeira and DeLucia, 2011; Ward et al., 2014), and ecosystem services worsened by these impacts (Turner et al., 2013). Land surface models, which can be coupled to a regional or global climate model, are used to simulate land-atmosphere interactions retrospectively or prospectively (Pitman, 2003) to identify intervention "hotspots" or develop realistic land management scenarios at the macroscale (Turner et al., 2007). Traditionally, spatially explicit LULCC was not an input to land surface models but was instead represented by structural (e.g., leaf area index) or physiological (e.g., stomatal resistance) changes in vegetation. LULCC was then mapped in parallel to characterize these changes. These early attempts have been replaced by fully coupled LULCC and land surface models (e.g., Shevliakova et al., 2009; Lawrence et al., 2012). Although the impact of LULCC on the Earth system is well established and quantifiable, studies remain sparse, due in part to the inadequacy of LULCC estimates (Pielke et al., 2011). In order to further land-atmosphere interaction research, LULCC models must be developed that provide consistent estimates over long historical time frames, regular (annual) intervals, and large spatial domains at $5 \mathrm{~km} \times 5 \mathrm{~km}$ spatial resolution; are projectable 50-100 years into the future; and use a consistent classification approach (Meiyappan et al., 2014; Rounsevell et al., 2014; Verburg et al., 2011).

Heistermann et al. (2006) reviews the two primary categories of macroscale LULCC models (geographic and economic), while Schaldach and Priess (2008) and Rounsevell et al. (2014) include reviews of blended or integrated approaches. The Conversion of Land Use and its Effects (CLUE) model (Veldkamp and Fresco, 1996; Verburg et al., 2002) is an example of a geographic technique. It identifies important social (population, economy, society, politics and planning, culture, and technology) and ecological (climate, vegetation, soil, topography, and hydrology) predictors from observed LULCC data, which are related to each other statistically, and then cellular automata are used to simulate competition between the predicted land use/cover types and neighboring grid cells based on these relationships. Decision rules are typically used iteratively to guarantee realistic LULC transitions occur. LandSHIFT (Alcamo et al., 2011) is an example of an economic approach because supply (LULC) is distributed on a grid cell basis by demand. Supply is determined from national estimates of crop yield and the net primary productivity of grasslands. Multi-criteria analysis, which involves applying cost functions and LULC constraints based on socio-ecological inputs, is used to define demand hierarchically and disaggregate supply over baseline or projected periods. Integrated approaches (e.g., CLUMondo: van Asselen and Verburg, 2013) are becoming more common, because they more adequately account for LULCC processes and the interaction of demand and trade with supply than economic or geographic models, respectively. Like most geographic and economic models, however, integrated models have a sound theoretical basis, but can be difficult to employ on a grid-cell basis at high spatial resolution at the macroscale, because of data inconsistencies and incongruities and model complexity that can propagate error, as well as the time and other resources needed to operate them. Earth observation (remote sensing) models are an important subcategory of the geographic approach because they overcome many of these challenges, making their operational use on a grid-cell basis at high spatial resolution at the macroscale more feasible.

Hansen and Loveland (2012) and Ban et al. (2015) present recent reviews of macroscale remote-sensing-based LULCC modeling. Remote sensing approaches use multivariate statistical techniques to classify land cover types based on the spectral or textural characteristics of gridded satellite data (DeFries et al., 1995). These approaches are simpler than integrated approaches, because they tend to capture change at a single resolution directly with no interaction between adjacent pixels. Remote sensing approaches, therefore, tend to be more parsimonious than integrated approaches and require less time for processing. Early remote sensing approaches involved daily coarse spatial resolution $(8 \mathrm{~km})$ Advanced Very High Resolution Radiometer (AVHRR) data available from 1981. Large disagreement and uncertainties in the models, due to mixed pixel effects from small LULC patch size, as well as diverse classification systems and methods, limited their use at the macroscale (Lepers et al., 2005). Recently, improved computational storage and processing and consensus on classification has facilitated the creation of consistent global LULCC maps at Landsat (30 m) resolution (Giri et al., 2013). GlobeLand30 (Chen et al., 2015), for example, uses a pixel-object-knowledge-based approach to classify Landsat images from spectrally derived vegetation indices globally in 2000 and 2010. The use of Landsat data alone poses serious challenges to modeling LULCC on an annual basis: persistent cloud cover and a 16-day revisit cycle make retrieval of cloud-free pixels difficult; the Landsat platforms have been retired (Landsat 5), have failed (Landsat 6), suffer from technical problems (Landsat 7), or have only recently become active (Landsat 8). To improve the temporal resolution and continuity of classification, other remote sensing products, such as the Global Forest Change product (Hansen et al., 2010), fuse Moderate-resolution Imaging Spectroradiometer (MODIS) data available every 1-2 days at $250-500 \mathrm{~m}$ spatial resolution with Landsat data. However, these products are only available over the MODIS era (2000-present), making long-term classification difficult. In short, the major draw- 
back of remote sensing approaches is that the temporal range and continuity necessary for long-term annual global change detection are often sacrificed for high $(\leq 500 \mathrm{~m})$ spatial resolution. Finally, remote sensing data are not projectable like other socio-ecological data, such as population density, precipitation, or temperature, limiting their use to retrospective analyses.

The purpose of this study was to propose a simple (functional) way to map LULCC at the macroscale at $5 \mathrm{~km} \times 5 \mathrm{~km}$ spatial resolution on an annual basis using socio-ecological predictors that are available on an annual basis and projectable 50-100 years into the future to facilitate landatmosphere modeling and research. The method was developed using sample area frames consisting of continuous land cover proportions developed from multi-year aerial and ground surveys in Kenya over a 30-year period. The approach was compared with remote sensing predictors that have been used to classify land cover types based on their phenology. Kenya is an ideal location to develop such a method because, like with many countries in sub-Saharan Africa (SSA), data are scarce compared to the Global North, and the impact of land modification on people and the environment is high (Lambin et al., 2003). In addition, (1) population density is highest in the most agriculturally productive areas due to unequitable land distribution and poor infrastructure (Jayne and Muyanga, 2012), making ecological determinants that are generally used to map LULCC potentially less relevant (Pricope et al., 2013); (2) agriculture is the primary source of livelihood and crops are mostly rainfed (Ngetich et al., 2014); and (3) interannual rainfall variability is high and frequently causes devastating droughts and floods (Held and Soden, 2006).

\section{Data and methods}

\subsection{Study area}

Aerial surveys were conducted in 1983, 1985, 2012, and 2013, to assess changes in land cover over parts of the Lake Victoria basin and central region of Kenya (Machakos and Makueni areas). The surveys yielded 2252 sample area frames of $5 \mathrm{~km} \times 5 \mathrm{~km}$ covering $28150 \mathrm{~km}^{2}$ or approximately $47 \%$ of Kenya's arable lands (Fig. 1). Olofsson et al. (2012) suggest that $5 \mathrm{~km} \times 5 \mathrm{~km}$ sample area frames are appropriate for evaluating macroscale LULCC models. The lakeshore and lowlands of Lake Victoria basin are primarily tropical, with one long rain season that extends from February to September (UNEP, 2008). The neighboring highlands follow a bimodal pattern and annual totals are higher than near the lakeshore, due to warm moist westerlies during the West African monsoon and orographic uplift. Central Kenya is drier and has two distinct rain seasons: long rains (MarchJune) and short monsoon rains (October-December). The Machakos area, which includes Muranga', Kiambu, and the

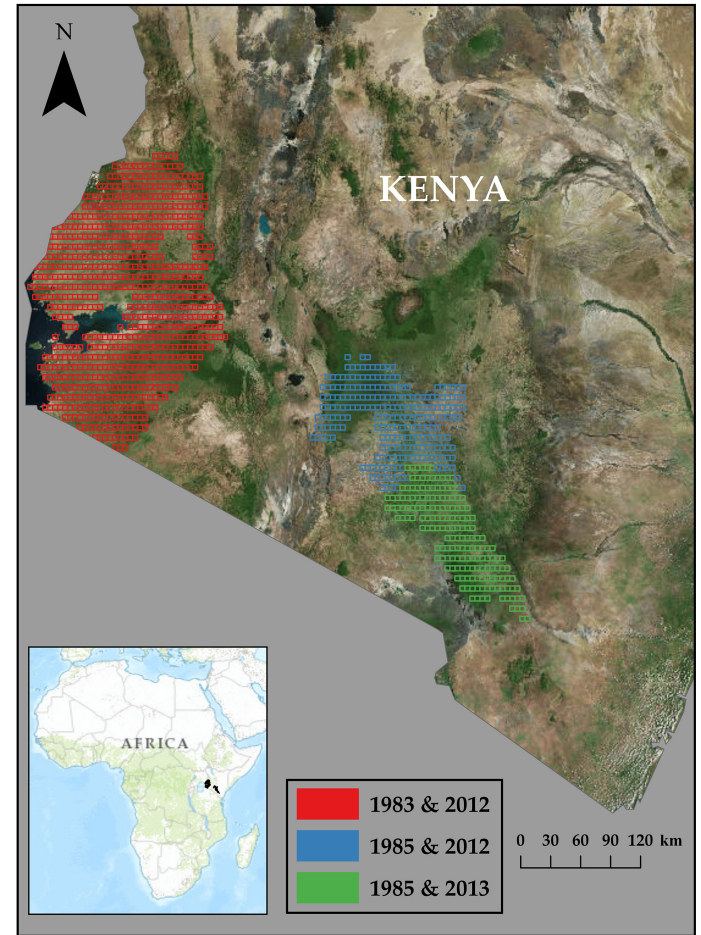

Figure 1. Study area: $112625 \mathrm{~km}^{2}$ sample frames demarcating the proportion of land use/cover types estimated from aerial photo interpretation and ground surveys. Photos were taken and surveys were performed in western Kenya in 1983 and 2012, north-central Kenya (Machakos area) in 1985 and 2012, and south-central Kenya (Makueni area) in 1985 and 2013. Source of remote sensing image and topographic map: Environmental Systems Research Institute (ESRI).

northern part of Machakos, is humid subtropical and therefore wetter than Makueni to the southeast, which is semiarid.

The probability (proportion) of various land cover types within each frame was available at two levels of specificity: level one (agriculture, natural vegetation, urban, and miscellaneous) and level two (crops, fallow, shrubs, savanna, wetlands, forest, and agroforestry). These two levels of specificity were analyzed to determine the level of detail that can be captured using coarse-resolution geospatial data. Continuous data were used, because at $5 \mathrm{~km} \times 5 \mathrm{~km}$ resolution, spatial heterogeneity makes discrete classification impractical. Agriculture included agroforestry, defined here as trees on a farm; crops (banana, coffee, maize, sugar cane, tea, wheat, and others); and pasture/fallow. Natural vegetation included savanna, shrubs (open and closed), wetlands (perennial and permanent), and forest (evergreen and deciduous). Urban included built-up structures, such as roads, homes, and towns. Miscellaneous included fish ponds and other water bodies, exposed rock, and charcoal pits. The frames were developed using an aerial point-sampling approach (Norton-Griffiths, 1988): several thousand geotagged aerial photos were taken over parallel transects spaced $1 \mathrm{~km}$ apart at approximately 
Table 1. Dates on which aerial sample surveys were conducted.

\begin{tabular}{lll}
\hline Sample region & First survey & Second survey \\
\hline Lake Victoria & November 1983 & October 2012 \\
Machakos & March-May 1985 & November-December 2012 \\
Makueni & June 1985 & February 2013 \\
\hline
\end{tabular}

$488 \mathrm{~m}$ (height above ground) in 1983/1985 and then again in 2012/2013, resulting in approximately seven aerial natural color analogue photos per frame with a ground sampling distance of $<1 \mathrm{~cm}$ in 1983/1985 and five aerial natural color digital photos per frame with a ground sampling distance of $6.5 \mathrm{~cm}$ in 2012/2013. The retrieval dates are shown in Table 1. A team of six technicians interpreted the photos on a rolling basis to minimize potential bias and errors that can occur from manual classification by different interpreters and for different years. The proportion of each land cover type (0-100\%) was determined by manually classifying a grid of 320 randomly distributed points superimposed over each photo. For each year, all land cover types were represented and classified, but not all frames were interpreted and classified (Fig. 1). The interpretations were validated via site visits and meetings with community stakeholders. The estimates were then averaged over the photos across interpreters to get the proportions for each frame. Further details on the 1983/1985 and 2012/2013 campaigns can be found in EcoSystems Ltd (1983, 1987), and Lamprey (2013).

\subsection{Macroscale data handling and processing}

The development of the functional relationships from the sample area frames involved four major steps illustrated in Fig. 2. Non-remote-sensing and remote sensing predictors were selected after an exhaustive online search that are freely and seamlessly available across SSA, so that the relationships can be used in future studies across the continent for retrospective or prospective analyses. Given the large number of predictors collected, machine learning was used to identify a subset of the most powerful predictors before constructing the functional relationships. The functional relationships were then evaluated against remote sensing predictors with hold-out samples and finally used to demonstrate how the relationships can be used to reconstruct LULCC estimates continuously through time.

Forty-three non-remote-sensing (climatic, hydrologic, socioeconomic, and topographic) and 16 remote sensing (phenological) predictors of land cover change were compared and subset for model building with the sample area frames. Either slowly changing (long-term average/one-time value) or dynamic predictors were considered. The slowly changing predictors and their sources are shown in Table 2. Using these predictors alone could streamline the modeling process. However, in reality, phenology, climate, and population change frequently, so these predictors were derived on an an-

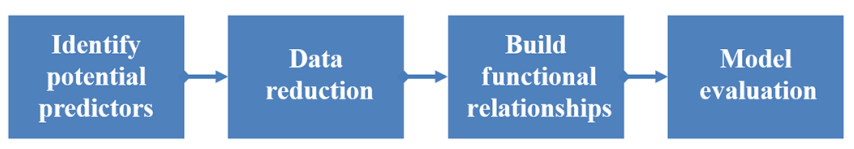

Figure 2. Model workflow.

nual basis as well. The handling and processing of annually changing or dynamic predictors are discussed in Sect. 2.2.12.2.3. For the remainder of the paper, dynamic predictors include a ".d" extension. All of the geospatial data were projected to Africa Equidistant Conic (m) to facilitate distance calculations. The predictors were resampled to the finest resolution data $(90 \mathrm{~m} \times 90 \mathrm{~m})$ and aggregated to $5 \mathrm{~km} \times 5 \mathrm{~km}$ resolution for model building.

\subsubsection{Climate}

Bioclimatic (BIOCLIM: Hijmans et al., 2005) variables were used to capture climatic differences in land cover types because they (1) provide biologically meaningful information and (2) have been projected mid-21st century at high spatial resolution for SSA (AFRICLIM: Platts et al., 2014). Two additional climate parameters were included in the analysis, because they are potentially relevant and part of the Platts et al. (2014) dataset: atmospheric demand for moisture (potential evapotranspiration - PET) and the moisture index. The BIOCLIM variables were computed on an annual basis from 1983-2012 using monthly temperature, shortwave incoming radiation, and precipitation. The variables were estimated using the "biovars" function in the "dismo" package in $\mathrm{R}$ (Hijmans et al., 2017). As with the Platts et al. (2014) dataset, PET was estimated using Hargreaves and Samani (1985).

The temperature/radiation and precipitation predictors were taken from the Princeton University high-resolution meteorological forcing (PHF) (Chaney et al., 2014) and the Climate Hazards Group InfraRed Precipitation with Stations (CHIRPS) (Funk et al., 2014) datasets, respectively. PHF originally spanned 1979-2008, but was extended to 2012 for this study. It is a downscaled version of the Princeton University Global Meteorological Forcing (PGF) dataset (Sheffield et al., 2006) for SSA. It assimilates new observation data, specifically station data from the US National Climatic Data Center (NCDC) Integrated Surface Database (ISD) and has undergone more rigorous correction than the global dataset. PHF is a blend of the most up-to-date observation-based, remote sensing, and reanalysis data sources: the National Centers for Environmental Prediction-National Center for Atmospheric Research (NCEP-NCAR) reanalysis, the Global Precipitation Climatology Project, the Tropical Rainfall Measuring Mission (TRMM), the Climatic Research Unit (CRU), and the Surface Radiation Budget. The data are downscaled using elevation. The dataset includes precipitation, minimum/maximum temperature, pressure, shortwave and longwave radiation, specific humidity, and wind speed at a daily 
Table 2. Slowly changing (long-term average/one-time value) predictors considered for LULCC estimation and their data sources. Climate, remote sensing, and population predictors were considered as annually changing as well. Dynamic (annual) variables are distinguished with a ".d" extension.

\begin{tabular}{|c|c|c|c|c|}
\hline Category & Variable & Description & Units & Source \\
\hline \multirow[t]{17}{*}{ Climate } & bio1 & Annual mean temperature & ${ }^{\circ} \mathrm{C}$ & $\begin{array}{l}\text { https://www.york.ac.uk/ } \\
\text { environment/research/kite/ } \\
\text { resources/ }\end{array}$ \\
\hline & bio2 & Mean diurnal range & ${ }^{\circ} \mathrm{C}$ & \\
\hline & bio3 & Isothermality & & \\
\hline & bio4 & Temperature seasonality & ${ }^{\circ} \mathrm{C}$ & \\
\hline & bio5 & Maximum temperature of warmest month & ${ }^{\circ} \mathrm{C}$ & \\
\hline & bio6 & Minimum temperature of coldest month & ${ }^{\circ} \mathrm{C}$ & \\
\hline & bio7 & Temperature annual range & ${ }^{\circ} \mathrm{C}$ & \\
\hline & bio10 & Mean temperature of warmest quarter & ${ }^{\circ} \mathrm{C}$ & \\
\hline & bio11 & Mean temperature of coldest quarter & ${ }^{\circ} \mathrm{C}$ & \\
\hline & bio12 & Annual precipitation & $\mathrm{mm}$ & \\
\hline & bio13 & Precipitation of wettest month & $\mathrm{mm}$ & \\
\hline & bio14 & Precipitation of driest month & $\mathrm{mm}$ & \\
\hline & bio15 & Precipitation seasonality & $\mathrm{mm}$ & \\
\hline & bio16 & Precipitation of wettest quarter & $\mathrm{mm}$ & \\
\hline & bio17 & Precipitation of driest quarter & $\mathrm{mm}$ & \\
\hline & $\mathrm{mi}$ & Moisture index & & \\
\hline & pet & Potential evapotranspiration & $\mathrm{mm}$ & \\
\hline \multirow[t]{3}{*}{ Hydrology } & dtw & Depth to groundwater & $\mathrm{mm}$ & $\begin{array}{l}\text { http://www.bgs.ac.uk/research/ } \\
\text { groundwater/international/ } \\
\text { africanGroundwater/maps.html }\end{array}$ \\
\hline & gwp & Groundwater productivity & $\mathrm{Ls}^{-1}$ & \\
\hline & gws & Groundwater storage & $\mathrm{mm}$ & \\
\hline \multirow[t]{8}{*}{ Phenological } & ampl & Linear amplitude & & $\begin{array}{l}\text { https://ecocast.arc.nasa.gov/data/ } \\
\text { pub/gimms/ }\end{array}$ \\
\hline & ampn & Nonlinear amplitude & & \\
\hline & lint & Linear intercept (annual mean) & & \\
\hline & nint & Nonlinear intercept (annual mean) & & \\
\hline & phsl & Linear phase & & \\
\hline & phsn & Nonlinear phase & & \\
\hline & strn & Nonlinear strength (asymmetry) & & \\
\hline & warpn & Nonlinear warp (asymmetry) & & \\
\hline Socioeconomic & popd & Population density & no. of people $\mathrm{km}^{-2}$ & $\begin{array}{l}\text { http://na.unep.net/siouxfalls/ } \\
\text { datasets/datalist.php }\end{array}$ \\
\hline \multirow[t]{4}{*}{ Topography } & asp & Aspect & $\circ$ & $\begin{array}{l}\text { http://www.cgiar-csi.org/data/srtm- } \\
\text { 90m-digital-elevation }\end{array}$ \\
\hline & elev & Elevation & $\mathrm{m}$ & \\
\hline & & Slope & $\%$ & \\
\hline & topind & Topographic wetness index & & \\
\hline
\end{tabular}

time step and $0.1^{\circ}(\sim 10 \mathrm{~km} \times 10 \mathrm{~km}$ at the Equator $)$ resolution. CHIRPS is available at pentad (5-day) intervals and $0.05^{\circ}(\sim 5 \mathrm{~km} \times 5 \mathrm{~km}$ at the Equator) spatial resolution from 1981 to 2012. Like PHF, CHIRPS is a blend of several observation-based, remote sensing, and reanalysis sources: geostationary thermal infrared satellite observations from the Climate Prediction Center and National Climatic Data Center, TRMM, and NOAA-NCAR. CHIRPS was selected as the precipitation data source over PHF, because it incorporates the largest collection of ground-based precipitation data in East Africa and bias correction is performed using the Climate Hazards Precipitation climatology (Funk et al., 2015). 


\subsubsection{Population density}

Population density was derived from the UNEP/GRID-Sioux Falls African Population Distribution Database (APDD) on an annual basis from 1983 to 2012. APDD consists of population density at a spatial resolution of $2.5 \mathrm{arcmin}$ ( $\sim 5 \mathrm{~km} \times 5 \mathrm{~km}$ at the Equator) for base years 1960, 1970, 1980, 1990, and 2000. The grids are derived from population statistics at various administrative (district, province, etc.) levels and temporal scales, depending on the availability of national population statistics. A detailed description of the derivation of gridded population can be found in Deichmann (1996). Each grid cell represents "population potential", based on its proximity to the transportation network (roads, railroads, and navigable rivers, and major towns/cities). Population at a given administrative level is then disaggregated according to the population potential. Grid cells that are closer to the network have higher coefficients and therefore receive a larger proportion of the population than grid cells further away. The base years are then extrapolated with an exponential growth/decay function (Davis, 1995). For consistency, the same function was used to distribute population between base years on an annual basis for each grid cell:

$P_{i, j, t}=P_{i, j, T} e^{\Delta t k_{i, j}}$

$k_{i, j}=\ln \left(P_{T+10 n} / P_{T+10(n-1)}\right) / 10$.

$P_{i, j, t}$ is the interpolated population/population density for a given year $(t)$ and at grid cell $i, j ; P_{i, j, T}$ is the population/population density for a given base year (period $=10$ years); $\Delta t$ is the change in time from the base year to the year being interpolated; and $k_{i, j}$ (Eq. 2) is the growth/decay coefficient. The growth/decay coefficient is defined by $P_{T+10(n-1)}$ (initial base year for iteration $n$ ) and $P_{T+10 n}$ (last base year for iteration $n$ ). The denominator was set to 10 , because $k_{i, j}$ accounted for decadal trends. After 2000, population statistics were extrapolated to 2012 using the 1990-2000 growth/decay coefficients.

\subsubsection{Remote sensing predictors}

The National Aeronautics and Space Administration's Global Inventory Modeling and Mapping Studies (GIMMS) normalized difference vegetation index (NDVI) version 3 (NDVI3g) (Pinzon and Tucker, 2014) was used to estimate the remote sensing predictors. NDVI is a ratio-based vegetation index derived from Earth observation (AVHRR) surface reflectance in the visible red and near infrared (NIR). NDVI approaching one (zero) is indicative of dense vegetation (bare soil). NDVI3g is available at $0.08^{\circ}(\sim 8 \mathrm{~km} \times 8 \mathrm{~km}$ at the Equator) spatial resolution and at a 15-day time step from 1983 to 2013. NDVI3g has been compared to other longterm global vegetation records and is considered the most appropriate for trend analyses (Tian et al., 2015).
The predictors were derived from NDVI using harmonic regression (Eastman et al., 2009) on an annual basis from 1983 to 2012. Linear harmonic regression estimates the amplitude (maximum) and phase (timing) of a fitted time series, but unless higher-order harmonics are introduced, linear harmonic regression is too rigid to account for outliers and multimodal regimes commonly found in the tropics. To overcome these obstacles, nonlinear harmonic regression (Carrão et al., 2010) was used to estimate five phenological predictors:

$\mathrm{NDVI}_{i, j, T}=M_{i, j}+A_{i, j} \cos \left(\omega_{0} t+\varnothing+\alpha \cos \left(\omega_{0} t+\varphi\right)\right)$,

where $\mathrm{NDVI}_{i, j, T}$ is NDVI at grid cell $i, j$ and over period $T$, which in this case was 24 , because nonlinear harmonic regression was computed on an annual basis from the 15day data; $M$ is the intercept (annual mean NDVI); $A$ is the amplitude; $\phi$ is the annual phase; and $\alpha$ and $\varphi$ are nonlinear terms defining the strength of nonlinearity (asymmetry) and nonlinear phase (deceleration/acceleration of asymmetry), respectively. The frequency $\left(\omega_{0}\right)$ equals $2 \pi / T$. The approach can be reduced to a linear harmonic oscillator by setting $\alpha \cos \left(\omega_{0} t+\varphi\right)$ to zero. The nonlinear predictors were derived at each grid cell using the "nlsLM" function in the "minipack.lm" package in R (Elzhov et al., 2016). The nlsLM function uses the Levenberg-Marquardt optimization method (Moré, 1978) to find the nonlinear least-squares fit. The function was constrained by the seed and boundary conditions described in Carrão et al. (2010). One thousand iterations at each grid cell were performed to avoid fitting local optima. Linear terms ( $A$ and $\phi$ ) were computed for the analysis as well, using the "lm" function in the "stats" package in R (https://cran.r-project.org/), because they are more efficient and are easier to interpret.

\subsection{Land cover model development using remote sensing and non-remote-sensing predictors}

Land cover models were developed for each level of specificity. Seventy percent of the samples $(N=1576)$ were used for model calibration and $30 \%$ of the samples $(N=676)$ were used for model validation.

Machine learning was used to omit redundant predictors and determine the feasibility of using the remaining predictors to predict each land cover type, given the large number of predictors and possible intercorrelations. Machine learning techniques lead to stable results when the number of predictors is large and are less affected by nonlinearity and multicollinearity than other automated fitting routines (FernándezDelgado et al., 2014). Breiman's random forest algorithm (Breiman, 2001) available in the "randomForest" package in $\mathrm{R}$ was selected in particular, because it is less susceptible to over-fitting and yields higher prediction accuracy than other machine learning algorithms. The random forest (RF) algorithm yields an ensemble model, bagged from multiple 
and independent decision trees consisting of various combinations of predictors and sample subsets. The performance of the ensemble was measured with a pseudo-coefficient of determination (pseudo- $R^{2}$ ), which is one minus the ratio of the cross-validated mean squared error (MSE) of the prediction to the variance of the observed data. As MSE or the average error between predicted and observed estimates approaches zero, $R^{2}$ approaches one (perfect correlation). The importance of each predictor in the ensemble is also quantified and is defined by the percent increase in cross-validated MSE when a predictor is removed from the ensemble. Once the predictors were ranked, the "rfcv" function was used to determine the number of predictors to use to develop functional relationships for each land cover class. The rfcv function computes the cross-validated MSE versus the number of predictors included in the ensemble in descending order of importance.

The drawback of RF is that it results in complex relationships that are difficult to interpret. Generalized additive models (GAMs) (Hastie and Tibshirani, 1990) were used to build functional relationships on the subsets of important predictors identified with RF because a number of studies have successfully estimated the proportion of crop area with socio-ecological predictors and GAMs (Grace et al., 2014; Husak et al., 2008; Marshall et al., 2011); like RF, GAMs are not severely impacted by nonlinear data, and unlike RF, GAMs are relatively simple and easy to interpret. Since the response variable (proportion of land cover type) was continuous and bounded from 0 to $100 \%$, the data were fitted using a quasi-binomial distribution (link: logistic). The logistic GAM predicts the log likelihood of an event (probability of success/probability of failure) using, in our case, a series of cubic spline functions:

$\log \left(\frac{p_{j}}{1-p_{j}}\right)=\beta_{0}+\sum f_{i, j}\left(x_{i, j}\right)$,

where $p$ is the probability of a LULC type for sample area frame $j, \beta_{0}$ is the intercept, and $f_{i, j}\left(x_{i, j}\right)$ is the cubic spline function for predictor $x_{i}$ at sample area frame $j$. The GAMs were developed with the "gam" function in the "mgcv" package in R. Model calibration was evaluated with explained part and overall deviance. Deviance is the log likelihood (probability space) alternative to variance. Part deviance is the deviance explained when the target predictor is removed from a GAM minus the overall deviance. Another pseudo- $R^{2}$ statistic ( 1 - model deviance/null deviance) was also computed to compare calibration with validation.

In order to demonstrate how the models can be used for macroscale application, the final GAMs developed were employed to reconstruct the annual change in agriculture and natural vegetation and to perform a trend analysis from 1983 to 2012 at each sample area frame. Trends were estimated using the Theil-Sen technique, which computes the median of all possible pairwise slopes in a time series. The approach has been used, for example, to measure long-term trends in

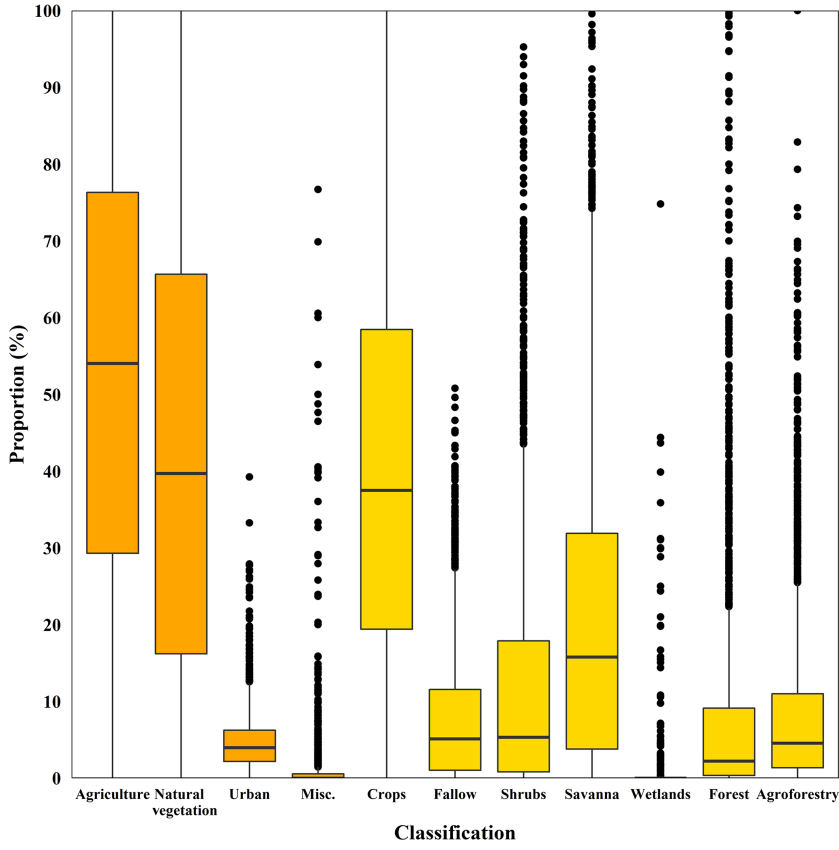

Figure 3. Box plot of the proportion of land cover types for two levels of classification $(N=2252)$. The first and second levels of classification are shaded in orange and yellow, respectively.

NDVI (de Beurs and Henebry, 2005), because it is not significantly impacted by outliers or nonlinearity. The significance of each trend was assessed using the Mann-Kendall statistic. Trends were masked at the $99.9 \%$ confidence band.

\section{Results}

\subsection{Land cover sample area frame summary}

The distribution of land cover over the sample area frames is illustrated with a box plot in Fig. 3. Agriculture and natural vegetation land cover (level one) were normally distributed, with agriculture having a higher median $(54.04 \%)$ and lower spread $(29.32$ and $76.33 \%$ at the first and third quartiles) than natural vegetation (median $=39.72 \%$, first quartile $=16.21 \%$, and third quartile $=65.67 \%$ ). The proportion of urban and miscellaneous land cover was considerably lower (median $=4.00$ and $0 \%$, respectively) and nonlinear, each having several high proportion outliers. The disaggregated land cover (level two) distributions, with the exception of crops, were nonlinear with long right tails. Crops represented the largest proportion of land cover $($ median $=37.52 \%)$ and had the largest spread (19.43 and $58.46 \%$ at the first and third quartiles), followed by savanna (median $=15.79 \%$, first quartile $=3.80 \%$, and third quartile $=31.91 \%)$. Wetlands represented the smallest proportion of land cover (median $=0 \%$ ), with sample area frames not exceeding $75 \%$, while forest represented the second 


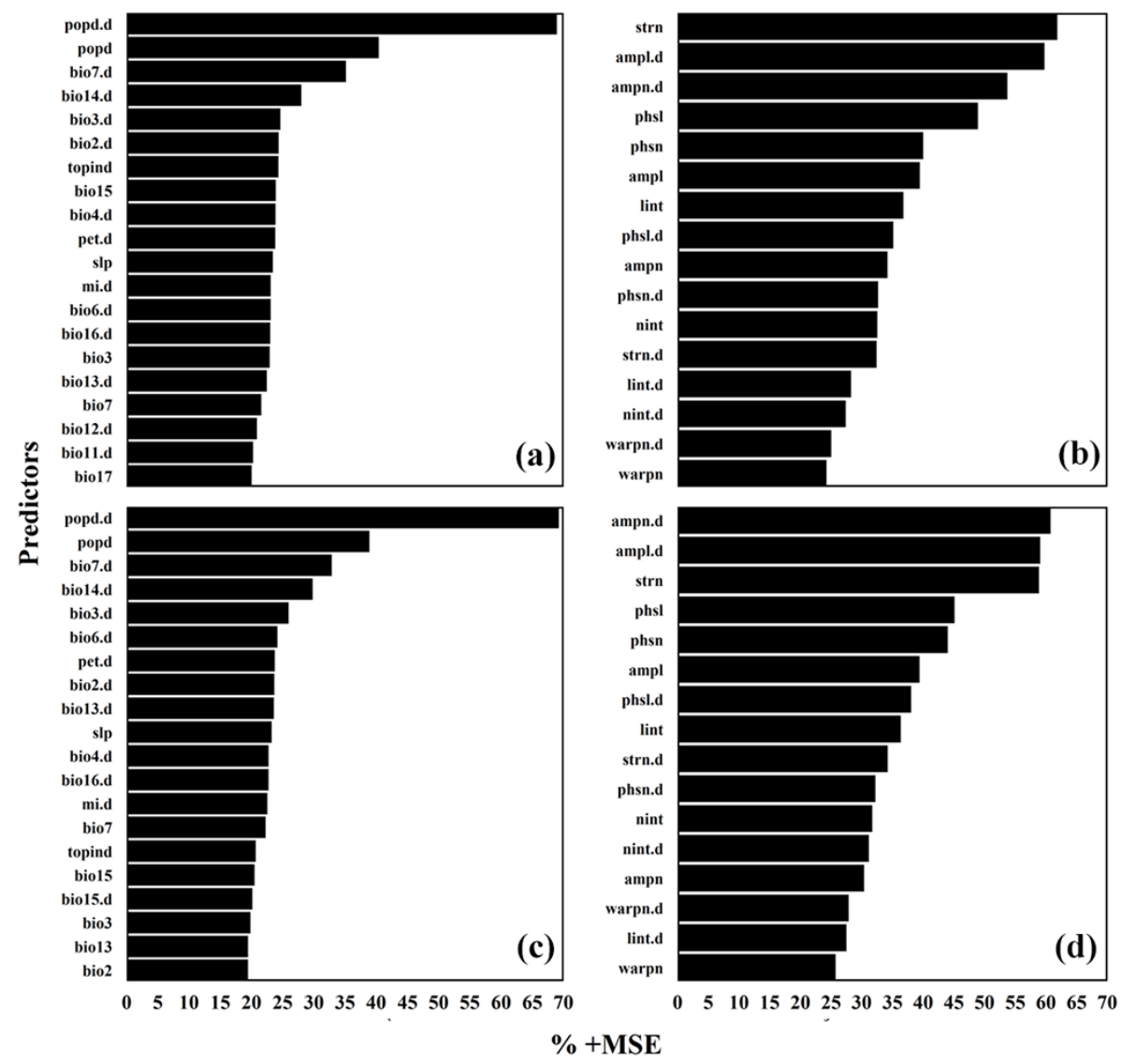

Figure 4. Percent mean squared error (MSE) increase after each of the top 20 non-remote-sensing (a, c) and 16 remote sensing (b, d) predictors were omitted from the random forest ensemble model predicting the proportion of agriculture and natural vegetation in the calibration sample frames, respectively. The models explained $69,49,69$, and $50 \%$ of the proportion variability.

smallest proportion of land cover $($ median $=2.22 \%)$ but had a large number of outliers.

\subsection{Data reduction}

The top remote sensing and non-remote-sensing predictors considered are ranked in descending order of importance for agriculture and natural vegetation using bar graphs in Fig. 4. The RF ensemble models using non-remotesensing predictors performed moderately well for agriculture (pseudo- $R^{2}=0.69$ ) and natural vegetation (pseudo$\left.R^{2}=0.69\right)$ but poorly for the more nonlinear distributions (urban pseudo- $R^{2}=0.37$ and miscellaneous pseudo$\left.R^{2}=0.50\right)$. The RF ensemble models using remote sensing predictors all performed poorly: agriculture (pseudo$R^{2}=0.49$ ), natural vegetation (pseudo- $R^{2}=0.50$ ), urban (pseudo- $R^{2}=0.22$ ), and miscellaneous (pseudo- $R^{2}=0.33$ ). It should be noted in each case, however, that the highestranked remote sensing predictors resulted in lower model error than the highest-ranked non-remote-sensing predictors. The non-remote-sensing predictors were more numerous and generated larger incremental improvements that contributed to overall greater predictive power. For the non-remotesensing ensembles, dynamic predictors were more important than slowly changing predictors, and population density and climate predictors consistently outranked topographic or hydrologic predictors. Popd.d, popd, bio7.d, bio14.d, and bio3.d were consistently ranked the most important predictors of agriculture and natural vegetation proportions. Omitting popd.d, the most important predictor for agriculture, for example, led to a more than $65 \%$ increase in ensemble MSE. Given that popd.d and popd were both important, model results were compared with popd.d and popd individually and combined as anomalies (popd.d / popd). Ensemble performance was better when the two predictors were considered separately. The most important remote sensing predictors were less influential than popd.d; strn, ampn.d, and ampl.d were more equally important for agriculture and natural vegetation, followed by phsl and phsn.

The importance of predictors of level two (crops, savanna, and forest) proportions is ranked in Fig. 5. The ranking was more variable for level two classification, but popd.d remained the most important predictor in each case. The level two RF ensemble models predicted less variabil- 


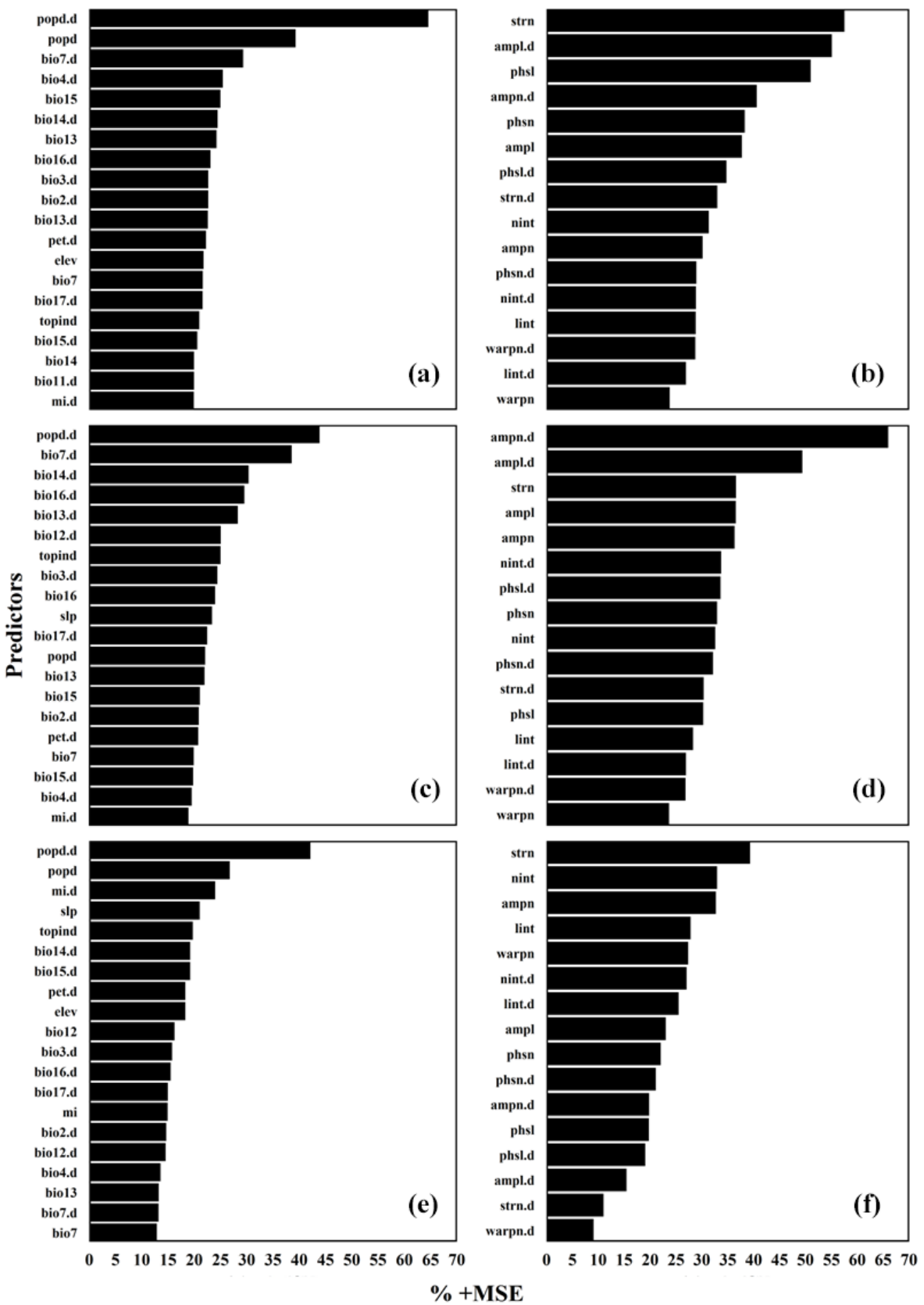

Figure 5. Percent mean squared error (MSE) increase after each of the top 20 non-remote-sensing (a, c, e) and 16 remote sensing (b, d, f) predictors were omitted from the random forest ensemble model predicting the proportion of crops, savanna, and forest in the calibration sample frames, respectively. The models explained $63,46,62,44,62$, and $46 \%$ of the proportion variability.

ity than the level one RF ensemble models and the nonremote-sensing predictors outperformed the remote sensing predictors when more than the highest-ranked predictors were introduced. The non-remote-sensing models performed moderately well for crops (pseudo- $R^{2}=0.63$ ), savanna (pseudo- $R^{2}=0.62$ ), and forest (pseudo- $R^{2}=0.61$ ) but poorly for fallow (pseudo- $R^{2}=0.42$ ), shrubs (pseudo$R^{2}=0.54$ ), wetlands (pseudo- $R^{2}=0.10$ ), and agroforestry (pseudo- $R^{2}=0.55$ ). Precipitation-based climatic predictors (bio12.d, bio13.d, bio14.d, and bio16.d) were more important in the savanna ensemble than temperature-based climatic determinants driving the crop ensemble. For the forest simulation, topographic predictors (slp and topind) were more important than most of the climatic predictors. The remote sensing ensembles performed poorly for all of the level two land cover classes: crops (pseudo- $R^{2}=0.46$ ), fallow (pseudo$R^{2}=0.33$ ), shrubs (pseudo- $R^{2}=0.44$ ), savanna (pseudo$R^{2}=0.44$ ), wetlands (pseudo- $R^{2}<1 \%$ ), forest (pseudo- 


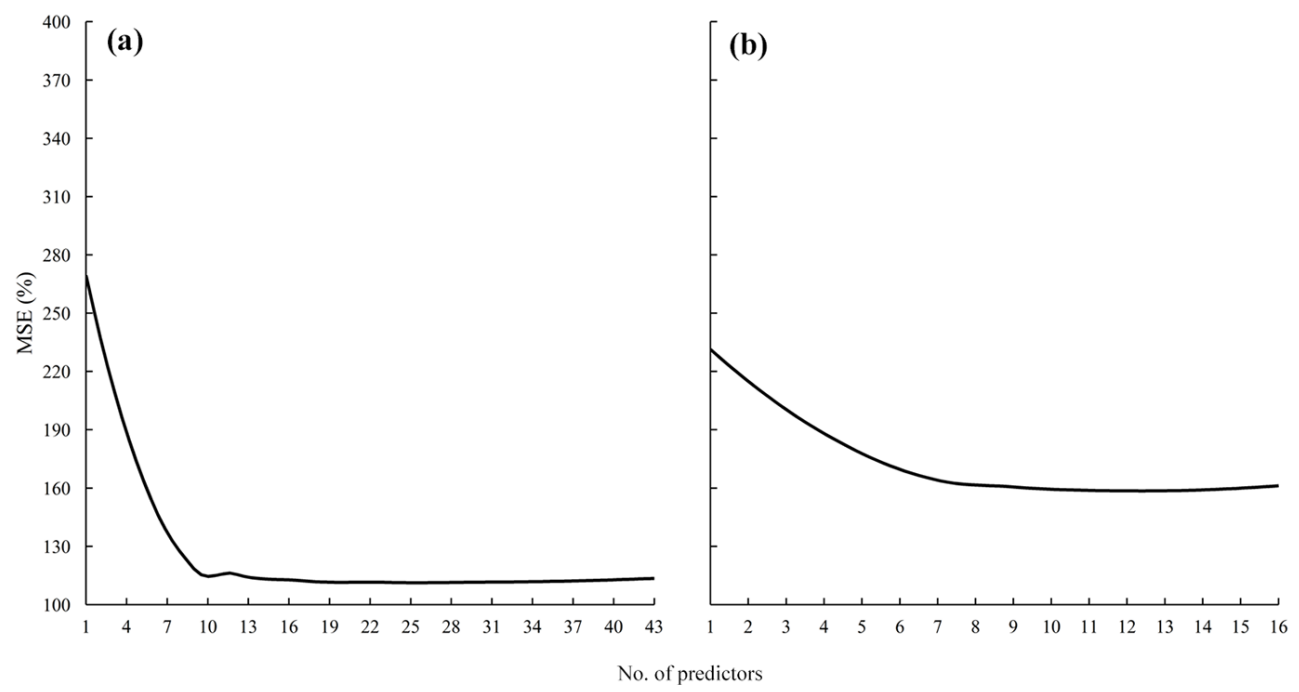

Figure 6. Curves showing the mean squared error (MSE) of the predicted proportion of forest from the random forest ensembles parameterized with non-remote-sensing (a) and remote sensing (b) predictors. The number of predictors corresponds to the bar graphs in descending order of importance.

$R^{2}=0.46$ ), and agroforestry (pseudo- $R^{2}=0.41$ ). For crops, strn and ampl.d remained the most important predictors. Maximum annual NDVI, as captured by ampl.d and ampn.d, was much more important for predicting the proportion of savanna. Unlike other ensembles, which were driven by dynamic predictors, the most important remote sensing predictors for forest cover were long-term averages.

\subsection{Building functional relationships}

The GAMs were developed for moderately performing land cover classes and used considerably fewer predictors than the RF ensembles, because most of the predictors in the ensembles explained very little, if any, variance. This is illustrated in Fig. 6, which shows MSE versus the number of predictors used in the non-remote-sensing and remote sensing ensembles for forest cover. For the non-remote-sensing ensemble, MSE increased from 119.76 to 120.49 after the 10th predictor and leveled off after the 13th predictor were introduced. For the remote sensing ensemble, MSE increased from 120.49 to 163.34 and leveled off after the 7th predictor was introduced. For this reason, the GAMs were built with $10-13$ of the highest-ranked non-remote-sensing predictors and additional predictors, namely popd, were removed after redundancies were identified in the GAM component functional plots and with significance tests (not shown). GAMs were not constructed using the remote sensing predictors because of the poor results of the ensembles and the inability of additional predictors to substantially improve the accuracy of the GAMs. Similarly, non-remote-sensing GAMs were not developed for urban, miscellaneous, fallow, shrubs, or wetlands.
Figures 7 and 8 show the functional relationships of the predictors used for estimating the proportion of agriculture and natural vegetation. Each model explained $61.5 \%$ (pseudo- $R^{2}=0.66$ ) and $61.4 \%$ (pseudo- $R^{2}=0.66$ ) of model deviance with nine and seven predictors, respectively. The error bars tended to be wider at proportion extremes, because fewer data points were available to train the models. The relative importance of each predictor, as defined by part deviance and other calibration statistics, is shown in Table 3 for the land cover types that were considered feasible for model building. Popd.d remained the most important predictor and uniquely explained $7.0-26.2 \%$ of model deviance. The log likelihood of agriculture (natural vegetation) increased (decreased) rapidly as population density increased from 0 to 550 people $\mathrm{km}^{-2}$, more gradually between 550 and 1200 people $\mathrm{km}^{-2}$, and reversed beyond 1200 people $\mathrm{km}^{-2}$. The predictive power of the topographic and climatic variables dropped off sharply compared to popd.d. For agriculture, bio14.d and topind were the second and third most important predictors but explained only 1.9 and $1.6 \%$ unique deviance. As seen in the partial functional plots, the proportion of agriculture was highest in high-production zones (medium population density) on ridges and crests where topind was low and for very wet tropical areas where bio14.d was high and semi-arid areas where bio14.d was low. For natural vegetation, temperature predictors, bio4.d and bio7.d, explained the second and third highest unique deviance after popd.d (2.0 and $1.3 \%)$. As seen in the functional plots, lowpopulation areas with more seasonal temperatures, or interannual variation, and lower bio3.d (isothermality) tended to have higher proportions of natural vegetation (savanna and shrubs). Isothermality is the ratio of mean diurnal temperature range (bio2.d) to the temperature annual range (bio7.d), 

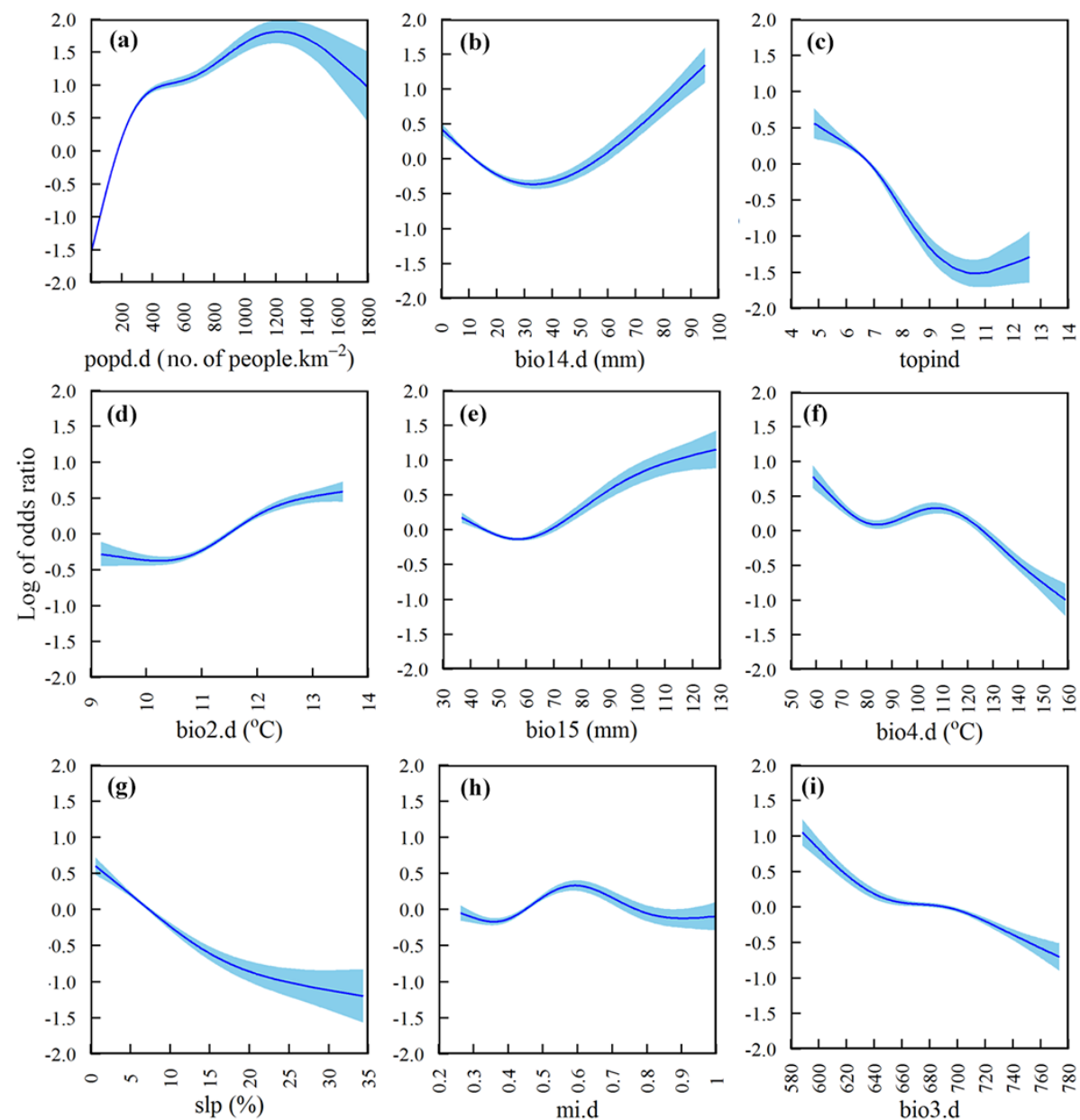

Figure 7. Partial functional plots relating the proportion (probability) of agriculture expressed as the log of odds ratio with (a) population density (popd.d), (b) precipitation of driest month (bio14.d), (c) topographic wetness index (topind), (d) mean diurnal range (bio2.d), (e) precipitation seasonality (bio15), (f) temperature seasonality (bio4.d), (g) slope (slp), (h) moisture index (mi.d), and isothermality (bio3.d). The probabilities are defined using a logistic model with cubic smoothing splines $(N=1,576)$.

which is the difference between the annual maximum and minimum temperatures. Areas that are less isothermal essentially have more pronounced seasons and are climatically less tropical. For the level two classifications, calibration was more difficult and yielded poorer relationships. Popd.d was the most important predictor and explained 7.0-16.4\% unique deviance. The predictive power of the topographic and climatic variables was more equally distributed than for the level one classification.

In all cases, the $R^{2}$ for the validation subset was lower than the pseudo- $R^{2}$ from the calibration subset: agriculture $\left(\Delta R^{2}=-0.04\right)$, natural vegetation $\left(\Delta R^{2}=-0.01\right)$, crops $\left(\Delta R^{2}=-0.03\right)$, savanna $\left(\Delta R^{2}=-0.01\right)$, and forest $\left(\Delta R^{2}=-0.06\right)$ (Fig. 9). With the exception of the crops GAM, level two GAMs tended to under-predict high proportions of land cover (savanna and forest) and contained numerous outliers.

\subsection{Trend analysis}

The GAMs for agriculture and natural vegetation were used to simulate trends in the annual proportions for the sample area frames from 1983 to 2012 as part of the evaluation to demonstrate how the approach could be used for a retrospective analysis. The proportion of agriculture for 1983 and 2012 is shown in Fig. 10a and b, while trends over the 30year period are shown in Fig. 10c. The high-potential agricultural zone (wet highlands) in western Kenya experienced the largest increase in simulated agricultural cover $(>1 \%$ per year or $30 \%$ over the 30 -year period). A time series of the strongest trend (1.68\% per year) is shown in Fig. 10d. Simulated population density was at 145 people $\mathrm{km}^{-2}$ in 1983 for this sample area frame, which steadily increased to 478 people $\mathrm{km}^{-2}$ by 2012. Closer to the lake, which consists of drier marginal mixed farming, trends were insignificant at the $99.9 \%$ confidence band or relatively weak $(<1 \%$ per year). Similar patterns were seen for the marginal mixed farming 
Table 3. Calibration statistics of the generalized additive models used to predict the proportion of land cover $(N=1576)$. Predictors are significant at the $99.9 \%$ confidence band.

\begin{tabular}{|c|c|c|c|c|}
\hline Land cover type & Variable ID & Part deviance $(\%)$ & Pseudo- $R^{2}$ & Deviance $(\%)$ \\
\hline \multirow[t]{9}{*}{ Agriculture } & popd.d & 20.0 & 0.66 & 61.5 \\
\hline & bio14.d & 1.9 & & \\
\hline & topind & 1.6 & & \\
\hline & bio2.d & 1.4 & & \\
\hline & bio15 & 1.3 & & \\
\hline & bio4.d & 1.2 & & \\
\hline & slp & 0.9 & & \\
\hline & mi.d & 0.8 & & \\
\hline & bio3.d & 0.7 & & \\
\hline \multirow[t]{7}{*}{ Natural vegetation } & popd.d & 26.2 & 0.66 & 61.4 \\
\hline & bio4.d & 2.0 & & \\
\hline & bio7.d & 1.3 & & \\
\hline & slp & 1.2 & & \\
\hline & bio14.d & 0.6 & & \\
\hline & bio3.d & 0.5 & & \\
\hline & pet.d & 0.4 & & \\
\hline \multirow[t]{8}{*}{ Crops } & popd.d & 15.5 & 0.56 & 52.1 \\
\hline & bio2.d & 3.5 & & \\
\hline & bio15 & 1.8 & & \\
\hline & bio3.d & 1.7 & & \\
\hline & bio4.d & 1.4 & & \\
\hline & pet.d & 1.0 & & \\
\hline & bio14.d & 0.7 & & \\
\hline & bio16.d & 0.7 & & \\
\hline \multirow[t]{8}{*}{ Savanna } & popd.d & 7.0 & 0.56 & 55.7 \\
\hline & bio13 & 3.7 & & \\
\hline & bio12.d & 2.4 & & \\
\hline & topind & 2.2 & & \\
\hline & bio16 & 2.2 & & \\
\hline & bio7.d & 1.6 & & \\
\hline & bio14.d & 1.6 & & \\
\hline & bio17.d & 1.4 & & \\
\hline \multirow[t]{10}{*}{ Forest } & popd.d & 16.4 & 0.57 & 61.2 \\
\hline & bio16.d & 4.3 & & \\
\hline & mi.d & 2.1 & & \\
\hline & bio3.d & 2.0 & & \\
\hline & bio12 & 1.6 & & \\
\hline & pet.d & 1.3 & & \\
\hline & elev & 1.0 & & \\
\hline & topind & 0.7 & & \\
\hline & bio14.d & 0.7 & & \\
\hline & slp & 0.7 & & \\
\hline
\end{tabular}

and high-potential agricultural zones of central Kenya. The only decrease in agricultural lands was in the town of Kitale $(-1.40 \%$ per year). The time series is also shown in Fig. 10d. Population density in Kitale was 1110 people $\mathrm{km}^{-2}$ in 1983 , which is near the threshold of declining agriculture cover versus population density at 1200 people $\mathrm{km}^{-2}$. By 2009, when the largest decrease in agriculture cover occurred, from
51.0 to $29.5 \%$, population density had steadily increased and surpassed another apparent threshold above 3000 people $\mathrm{km}^{-2}$. The direction and relative magnitude of trends in natural vegetation (not shown) generally corresponded inversely to trends in agriculture, but were negatively weak (maximum $=-0.4 \%$ per year or $-12 \%$ over the 30 -year period). 

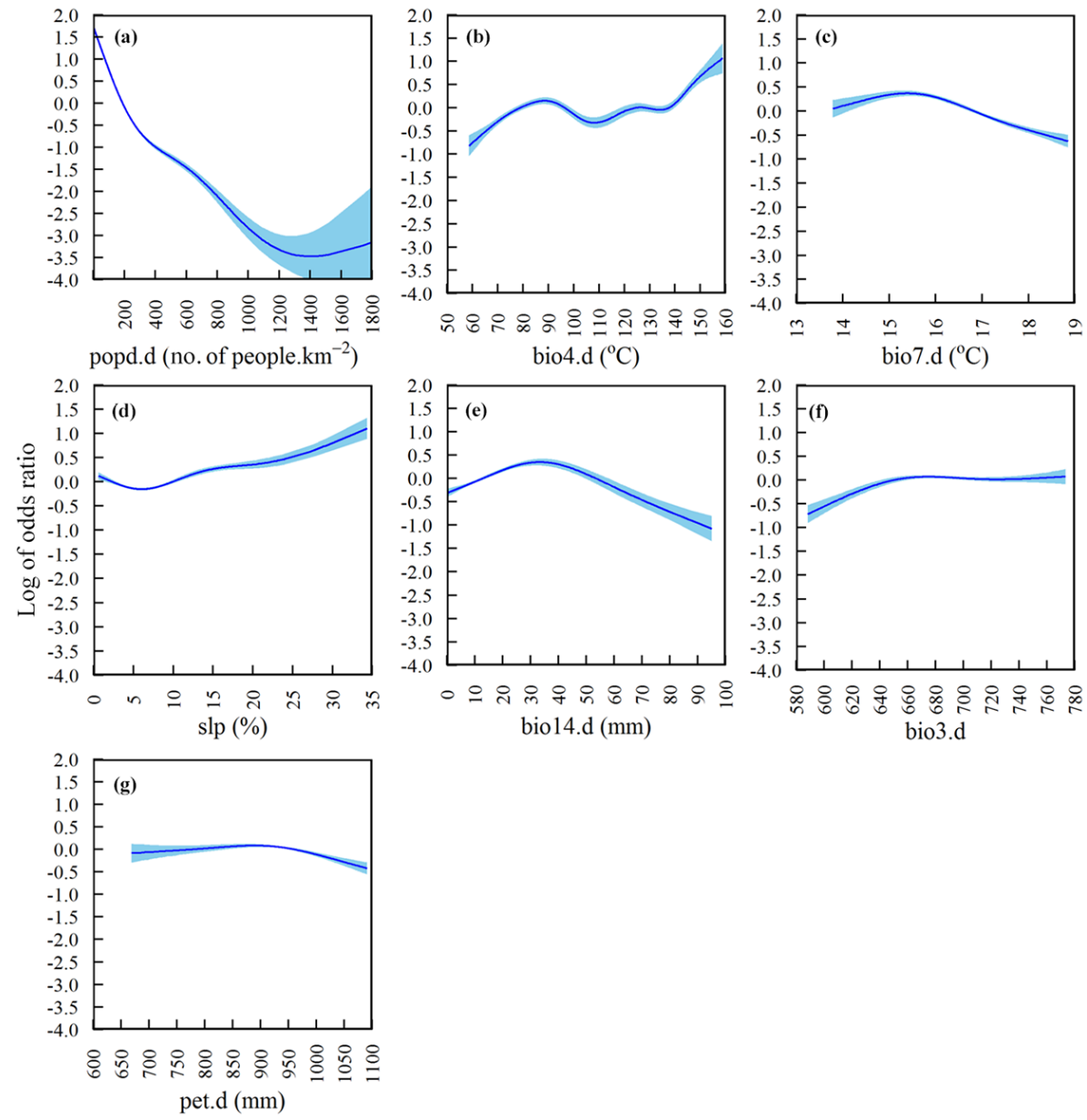

Figure 8. Partial functional plots relating the proportion (probability) of natural vegetation expressed as the log of odds ratio with (a) population density (popd.d), (b) temperature, seasonality (bio4.d), (c) temperature annual range (bio7.d), (d) slope (slp), (e) precipitation of the driest month (bio14.d), (f) isothermality (bio3.d), and (g) potential evapotranspiration (pet.d). The probabilities are defined using a logistic model with cubic smoothing splines $(N=1576)$.

\section{Discussion}

The results make three important contributions that the land surface modeling community should consider to improve LULCC detection, particularly for SSA: (1) a socioeconomic variable (population density) was the highest-ranked predictor of LULCC and had considerably more predictive power than biophysical predictors, (2) non-remote-sensing predictors outperformed remote sensing predictors due to their number and the incremental improvement in the predictive power of each, and (3) coarse-resolution data were able to capture general classification descriptors, but unable to capture more detailed descriptors.

The global increase in agricultural land cover has been attributed to the demand for food and other agricultural commodities by a growing population (Pongratz et al., 2008). In SSA, smallholder farms, which support the majority of the labor force, are small (half are $<1.5 \mathrm{ha}$ ) and concentrated in densely populated areas, while large portions of arable farmland in sparsely populated areas remain underutilized (Jayne et al., 2003). This underutilization is due primarily to a lack of investment in infrastructure and unequitable tenure systems, which forces farmers to grow more on less land. This relationship is confirmed by rural population survey data in Kenya, which showed that fertilizer input use and net farm income per hectare increase until approximately 550 people $\mathrm{km}^{-2}$ and then sharply decline, because farm sizes shrink, surplus production decreases, and farmers must adopt costlier strategies (e.g., zero-grazing) to maximize revenue (Jayne and Muyanga, 2012). The functional relationship for population density and steady increase in area under cultivation in high-production zones demonstrated by the trend analysis in this study, corresponds to this finding, as area under cultivation increased rapidly to approximately 550 people $\mathrm{km}^{-2}$ and then increased more gradually with higher population density until 1200 people $\mathrm{km}^{-2}$. Few sample area frames had population densities greater than 

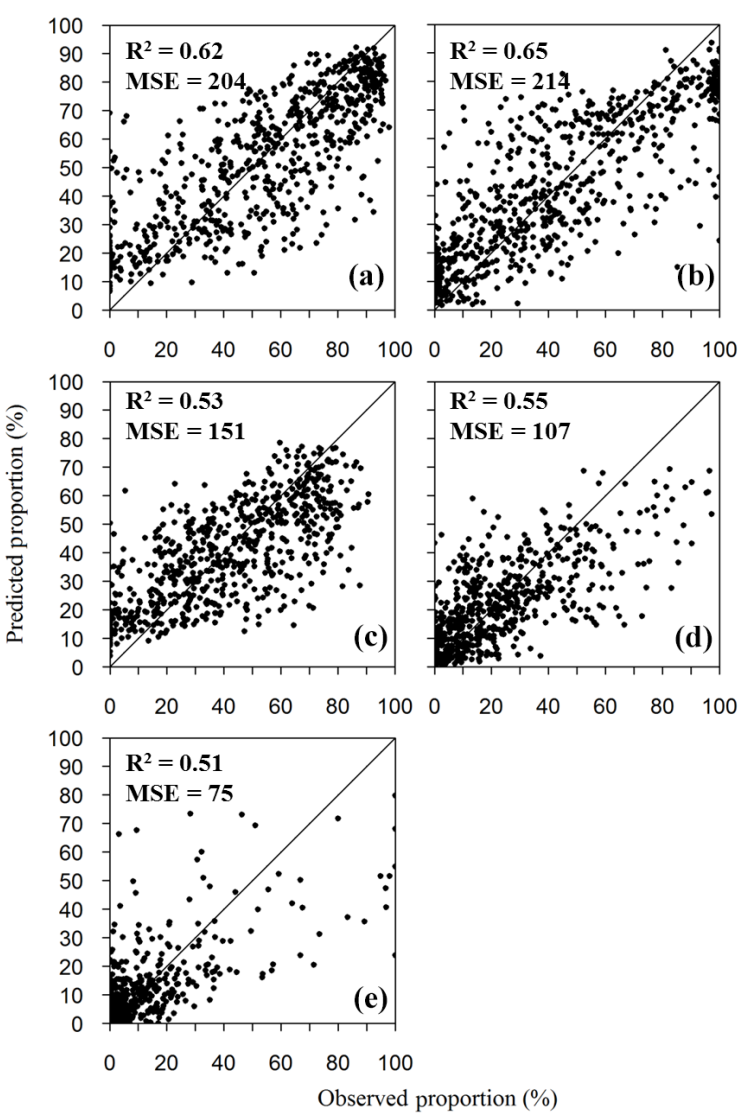

Figure 9. Predicted versus observed proportion of agriculture (a); natural vegetation (b); crops (c); savanna (d); and forest (e) for the validation subset $(N=676)$. The $1: 1$ line is drawn through the origin.

1200 people $\mathrm{km}^{-2}$, as in Kitale, so it is difficult to know whether this functional relationship holds for very high population densities. At least to 2008, Kitale experienced a growth rate of $12 \%$, well above the national average $(7 \%)$, due to persistent drought and out-migration from neighboring highproduction zones (Majale, 2008). Although the functional relationship for population density corroborates household surveys in Kenya and other agrarian countries in SSA, it should be further scrutinized, because land tenure in SSA is complex (Place, 2009), the dependency of LULCC predictors on location and spatial scale can be high (Rindfuss et al., 2004), and the transition from agrarian to industrialized nations may make 50-100-year projections for SSA obsolete.

The proposed methodology when applied to other regions of the world will undoubtedly result in a different combination of socio-ecological predictors and functional relationships, because access to land varies across agrarian and nonagrarian societies, so further study is required with observed data to develop region-specific models and validate the results for countries in SSA. Kumar et al. (2013), for example, showed that in the United States pre-1900, when the country was largely agrarian and transportation networks were weak, population density and crop area were directly correlated, because crops needed to be grown close to markets. However, as the country became more industrialized and transportation networks improved, farmers moved to more biophysically suitable areas away from city centers, making biophysical determinants of crop area more important than population density in the latter half of the 20th century. Whether the analyses are performed in agrarian or non-agrarian regions, extensive preparation of observation data will be required, because the data used in this study, namely consistent sample area frames at a spatial resolution appropriate for land surface modeling and spanning multiple climatic zones through time, are quite unique.

Population density estimates vary widely (Wilson, 2014), and given its fundamental importance to the proposed model framework, future work should aim to integrate a more dynamic product that better accounts for interannual variability and realistic representation of current and projected population density. To the authors' knowledge, this was the first attempt to make a population product dynamic. However, the approach is essentially tracking decadal trends that explain a significant portion of interannual variability. In reality, population density can show high interannual variability due to migration and other factors. Regarding the product itself, changes in population density do not necessarily "grow" from transportation networks and are influenced by important feedbacks now and in the future. In addition, the extrapolation method used is efficient and can be projected indefinitely, but does not capture complex demographics that other methods do and can lead to "runaway" growth/decline and unrealistic mid- to late-21st century projections for scenariobuilding (Baker et al., 2008). Finally, there is no consensus on which population product to use however, in the future, other products (e.g., Afripop) should be compared against the product used here, used to adjust growth/decay coefficient for population density estimates beyond 2000 , or combined to make a model ensemble.

This paper highlights the importance of gridded socioeconomic data in mapping LULCC, but gridded macroscale datasets are almost exclusively biophysical in nature. The biggest gains in LULCC prediction could be made, therefore, by developing gridded macroscale socioeconomic data from existing country-level products, such as the human development index. More minor gains could be made by integrating biophysical predictors not used in this study, such as soil type and properties. Gridded soils data exist globally from the International Soil Reference and Information Center but were not considered in this study, because they are one-time values and do not capture the dynamic nature of soils or its complex relationship with LULCC. A dynamic soils product was recently developed for the MODIS era (see Vågen et al., 2016) and could be a powerful tool for LULCC detection, especially if it is back-casted over the full temporal range of other predictors. Many biophysical predictors are avail- 

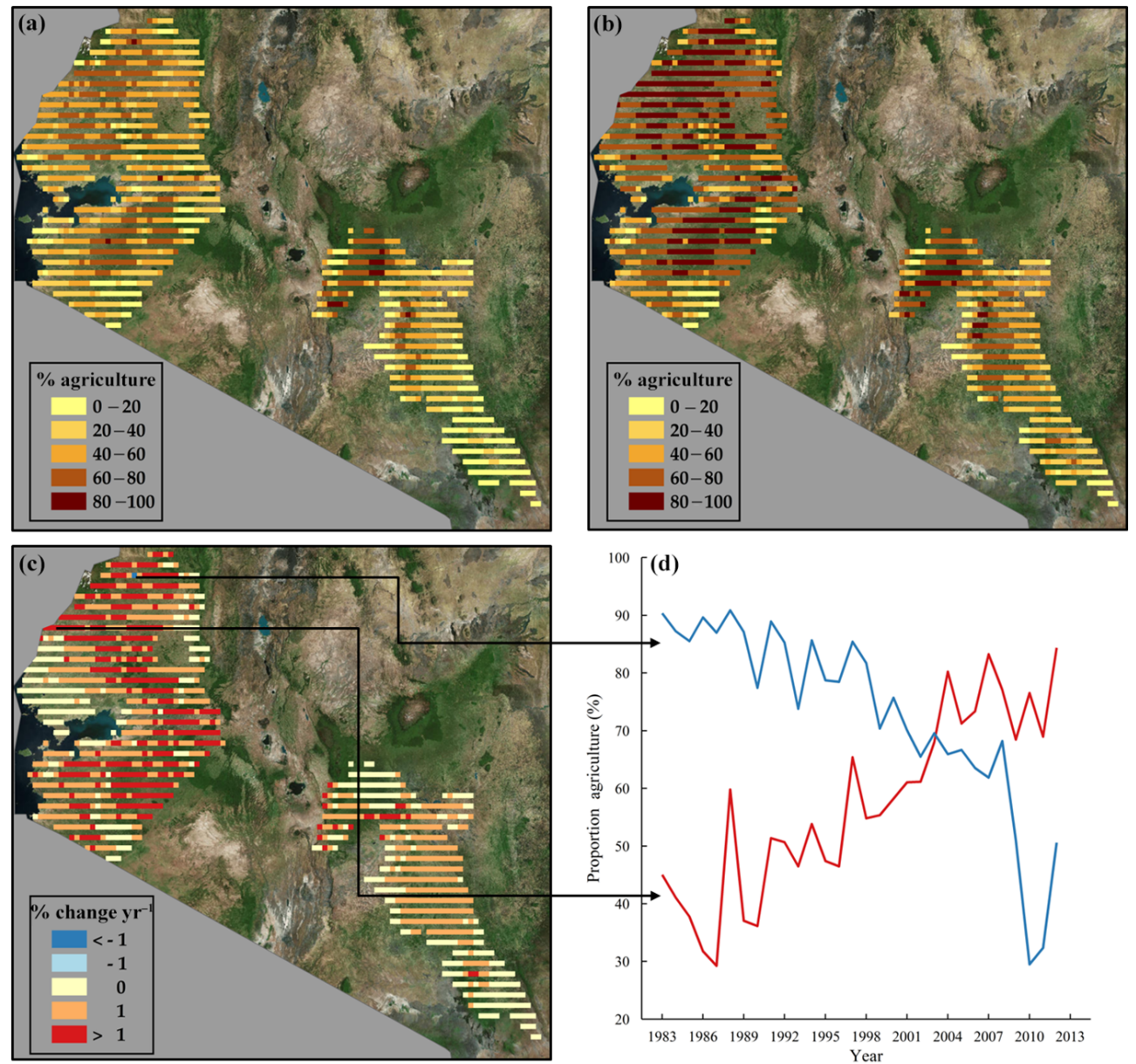

Figure 10. Simulated percent agriculture for sample area frames in 1983 (a) and 2012 (b), change in agriculture per year over the 30 year (1983-2012) period (c), and time series of the strongest positive (red) and negative (blue) trend (d). Trends were determined with a Theil-Sen estimator and masked for significance using the Man-Kendall statistic at the $99.9 \%$ confidence band.

able mid- and late 21 st century and are therefore widely used for prospective analyses, so methods should be explored to project soils and socio-economic data into the future to improve LULCC estimates.

Grace et al. (2014) developed GAMs to predict cropped area in Kenya using biophysical predictors (rainfall, elevation, NDVI, slope, and the topographic wetness index) and explained much of the deviance in cropped area (41.9$81.4 \%)$. Although the models used different predictors for different years and production zones, and the definition of cropped area and the degree of functional smoothing were not explicit, the study shows that the intercorrelation among predictors may be obscuring the importance of biophysical determinants. Specifically, population density tends to be highly correlated with and could be suppressing the explanatory power of biophysical predictors, though the partial deviance statistics did not reflect this. In addition, the random forest algorithm accounts for intercorrelation to some degree, but other techniques could be introduced to further reduce these effects. For example, principal component anal- ysis could be used to develop temperature and precipitation indices that integrate all or some of the BIOCLIM predictors.

Phenological patterns extracted from continuous Earthobservation-based NDVI have been widely used to map LULCC over long time periods, given the lack of higher spatial and spectral resolution data before the MODIS era (Ali et al., 2014; de Bie et al., 2012). These studies show that vegetation periodicity is highly variable for a given land cover type and that long-term averages of phenological predictors are more reliable for mapping LULCC. In this study, many of the important remote sensing predictors (particularly for forests) were long-term averages, but they still under-predicted LULCC when compared against nonremote-sensing predictors, which were more numerous and resulted in larger incremental improvements to model accuracy. Perhaps the main difficulty in using long-term Earth observation data for LULCC estimation is the coarseness of the data and the rapid change in vegetation that often occurs over small spatial scales. Population density, which was a much stronger predictor, on the other hand, may well be 
captured using coarse-resolution data, because this predictor changes more gradually over space. An analysis of the non-remote-sensing and remote sensing predictors together revealed that for agriculture, natural vegetation, savanna, and forest cover, Earth observation data provided an additional 1-2\% explained deviance. If the long-term average remote sensing predictors could be downscaled using MODIS or Landsat data and then aggregated to $5 \mathrm{~km} \times 5 \mathrm{~km}$ resolution with distribution moments as predictors, for example, the explanatory power of non-remote-sensing predictors could be further enhanced for retrospective analyses. Another avenue worth exploring could involve using downscaled long-term average remote sensing predictors to develop $5 \mathrm{~km} \times 5 \mathrm{~km}$ probabilities as in the Pengra et al. (2015) dataset to evaluate the non-remote-sensing models proposed here.

The evaluation of the models at two levels of specificity revealed that coarse resolution is able to better simulate general descriptors, such as natural vegetation, but is poorer at predicting more detailed descriptors, such as forest. Each of the more detailed random forest ensembles with non-remotesensing predictors had $\Delta R^{2} \mathrm{~s}$ of $-0.06,-0.07$, and -0.07 for crop, savanna, and forest over agriculture and natural vegetation, respectively. Part of this discrepancy can be attributed to the increased interpretation uncertainty, as interpreters find it more challenging to distinguish between more detailed LULC types. In addition, coarse-resolution data may not be able to capture the level of heterogeneity in the area sample frames needed to distinguish land-use/cover-specific socio-ecological patterns and properties.

\section{Conclusion}

This study developed and evaluated a simple method to provide consistent estimates of LULCC annually over 30 years at $5 \mathrm{~km} \times 5 \mathrm{~km}$ resolution using non-parametric functional relationships with a small subset of socio-ecological predictors $(p \leq 10)$. Functional relationships were developed after data-mining 43 geospatial datasets that are available seamlessly across SSA, which can be used for retrospective or prospective mid- and late-21st century analyses as well. The relationships are intuitive and tunable, making their use practical for decision makers to identify intervention hotspots and develop land management scenarios. Model validation, performed with the proportion of major land cover types in Kenya over a 30-year period, revealed that a number of activities should be performed to improve the predictive power of the models for practical use. These activities should include integrating improved existing or newly developed spatially explicit geospatial (particularly socioeconomic) datasets into the proposed model framework. With these improvements, land surface and LULCC modeling could be greatly enhanced and the consequence of the latter on the Earth system more fully understood. In an upcoming study, the modeling approach proposed here will be used with a newly acquired sample area frame dataset to estimate historical LULCC and project land suitability across SSA mid-21st century with AFRICLIM and population statistics.

\section{Data availability}

All input geospatial data, sample area frame proportions of land use/cover, and model outputs will be made freely available on the World Agroforestry Centre's Landscapes Portal (http://landscapeportal.org/). Other data used in this study not on the Landscapes portal, including AFRICLIM (Platts et al., 2014), quantitative groundwater maps for Africa (MacDonald et al., 2012), GIMMMS NDVI3g (Pinzon and Tucker, 2014), UNEP/GRID, 1987, CGIAR-CSI SRTM 90m (Jarvis et al., 2008), CHIRPS (Funk et al, 2014), and PHF (Chaney et al., 2014), are available at https://www.york.ac. uk/environment/research/kite/resources/; http://www.bgs.ac. uk/research/groundwater/international/africanGroundwater/ maps.html; https://ecocast.arc.nasa.gov/data/pub/gimms/; http://na.unep.net/siouxfalls/datasets/datalist.php; http://www.cgiar-csi.org/data/srtm-90m-digital-elevation; http://chg.geog.ucsb.edu/data/; and http://hydrology. princeton.edu/data.php.

Competing interests. The authors declare that they have no conflict of interest.

Acknowledgements. The work summarized in this manuscript was primarily funded through support by the CGIAR Research Program on Climate Change, Agriculture and Food Security for the project titled "Multi-disciplinary species distribution modelling for "climate smart" agriculture in East Africa". Additional support for the early field and aerial surveys was supported by the Kenyan Lake Basin Development Authority and Ministry of Planning and National Development. We would like to extend our special thanks to Sandra Nakibilango, Dorcas Ninsiima, Charles Ngugi, Patrick Ojorot, and Samuel Olowo, who interpreted the aerial photos taken for this project; Bernadette Apio, who coordinated the interpreter team; and Juliet Kyakobyewo, who entered the data into our database. Finally, we would like to thank Eike Luedeling, who initially led and organized the project.

Edited by: Z. Xie

Reviewed by: five anonymous referees

\section{References}

Alcamo, J., Schaldach, R., Koch, J., Kölking, C., Lapola, D., and Priess, J.: Evaluation of an integrated land use change model including a scenario analysis of land use change for continental Africa, Environ. Model. Softw., 26, 1017-1027, 2011.

Ali, A., de Bie, C. A. J. M., Skidmore, A. K., Scarrott, R. G., and Lymberakis, P.: Mapping the heterogeneity of natural and seminatural landscapes, Int. J. Appl. Earth Obs., 26, 176-183, 2014. 
Anderson-Teixeira, K. J. and DeLucia, E. H.: The greenhouse gas value of ecosystems, Glob. Change Biol., 17, 425-438, 2011.

Baker, J., Ruan, X., Alcantara, A., Jones, T., Watkins, K., McDaniel, M., Frey, M., Crouse, N., Rajbhandari, R., Morehouse, J., Sanchez, J., Inglis, M., Baros, S., Penman, S., Morrison, S., Budge, T., and Stallcup, W.: Density-dependence in urban housing unit growth: An evaluation of the Pearl-Reed model for predicting housing unit stock at the census tract level, J. Econ. Soc. Meas. 33, 155-163, 2008.

Ban, Y., Gong, P., and Giri, C.: Global land cover mapping using Earth observation satellite data: Recent progresses and challenges, ISPRS J. Photogramm., 103, 1-6, 2015.

Binder, H. and Tutz, G.: A comparison of methods for the fitting of generalized additive models, Stat. Comput., 18, 87-99, 2007.

Breiman, L.: Random Forests, Mach. Learn., 45, 5-32, 2001.

Carrão, H., Gonalves, P., and Caetano, M.: A Nonlinear Harmonic Model for Fitting Satellite Image Time Series: Analysis and Prediction of Land Cover Dynamics, IEEE T. Geosci. Remote, 48, 1919-1930, 2010.

Chaney, N. W., Sheffield, J., Villarini, G., and Wood, E. F.: Development of a High-Resolution Gridded Daily Meteorological Dataset over Sub-Saharan Africa: Spatial Analysis of Trends in Climate Extremes, J. Climate, 27, 5815-5835, doi:10.1175/JCLI-D-13-00423.1, 2014 (data available at: http:// hydrology.princeton.edu/data.php, last access: 18 August 2016).

Chen, J., Chen, J., Liao, A., Cao, X., Chen, L., Chen, X., He, C., Han, G., Peng, S., Lu, M., Zhang, W., Tong, X., and Mills, J.: Global land cover mapping at $30 \mathrm{~m}$ resolution: A POK-based operational approach, ISPRS J. Photogramm., 103, 7-27, 2015.

Davin, E. L. and de Noblet-Ducoudré, N.: Climatic Impact of Global-Scale Deforestation: Radiative versus Nonradiative Processes, J. Climate, 23, 97-112, 2010.

Davis, H. C.: Demographic Projection Techniques for Regions and Smaller Areas: A Primer, UBC Press, Vancouver, Canada, UBC Press, 116 pp., 1995.

de Beurs, K. M. and Henebry, G. M.: A statistical framework for the analysis of long image time series, Int. J. Remote Sens., 26, 1551-1573, 2005.

de Bie, C. A. J. M., Nguyen, T. T. H., Ali, A., Scarrott, R., and Skidmore, A. K.: LaHMa: a landscape heterogeneity mapping method using hyper-temporal datasets, Int. J. Geogr. Inf. Sci., 26, 2177-2192, 2012.

DeFries, R. S., Field, C. B., Fung, I., Justice, C. O., Los, S., Matson, P. A., Matthews, E., Mooney, H. A., Potter, C. S., Prentice, K., Sellers, P. J., Townshend, J. R. G., Tucker, C. J., Ustin, S. L., and Vitousek, P. M.: Mapping the land surface for global atmosphere-biosphere models: Toward continuous distributions of vegetation's functional properties, J. Geophys. Res.-Atmos., 100, 20867-20882, 1995.

Deichmann, U.: A Review of Spatial Population Database Design and Modeling (Technical Report No. 96-3), National Center for Geographic Information and Analysis, Santa Barbara, CA, 1996.

Eastman, R., Sangermano, F., Ghimire, B., Zhu, H., Chen, H., Neeti, N., Cai, Y., Machado, E. A., and Crema, S. C.: Seasonal trend analysis of image time series, Int. J. Remote Sens., 30, 27212726, doi:10.1080/01431160902755338, 2009.

EcoSystems Ltd: Integrated Land Use Survey: Final Report. Lake Basin Development Authority, Kisumu, Kenya, 1983.
EcoSystems Ltd: Integrated Land Use Database for Kenya. Minstry of Planning \& Natural Development, Nairobi, Kenya, 1987.

Elzhov, T. V., Mullen, K. M., Spiess, A. N., and Bolker, B.: R Interface to the Levenberg-Marquardt Nonlinear Least-Squares Algorithm Found in MINPACK, Plus Support for Bounds, 14 pp., Repository, CRAN, 2016.

Fernández-Delgado, M., Cernadas, E., Barro, S., and Amorim, D.: Do We Need Hundreds of Classifiers to Solve Real World Classification Problems? J. Mach. Learn. Res., 15, 3133-3181, 2014.

Funk, C., Peterson, P., Landsfeld, M., Pedreros, D., Verdin, J., Rowland, J., Romero, B., Husak, G. J., Michaelsen, J., and Verdin, A.: A Quasi-Global Precipitation Time Series for Drought Monitoring (No. 832), US Geological Survey Data Series, US Geological Survey, Washington, DC, available at: http://chg.geog.ucsb.edu/ data/ (last access: 15 Feburary 2015), 2014.

Funk, C., Verdin, A., Michaelsen, J., Peterson, P., Pedreros, D., and Husak, G.: A global satellite-assisted precipitation climatology, Earth Syst. Sci. Data, 7, 275-287, doi:10.5194/essd-7-275-2015, 2015.

Giri, C., Pengra, B., Long, J., and Loveland, T. R.: Next generation of global land cover characterization, mapping, and monitoring, Int. J. Appl. Earth Obs., 25, 30-37, 2013.

Grace, K., Husak, G., and Bogle, S.: Estimating agricultural production in marginal and food insecure areas in Kenya using very high resolution remotely sensed imagery, Appl. Geogr., 55, 257265, 2014.

Hansen, M. C., Stehman, S. V., and Potapov, P. V.: Quantification of global gross forest cover loss, P. Natl. Acad. Sci. USA, 107, 8650-8655, 2010.

Hansen, M. C. and Loveland, T. R.: A review of large area monitoring of land cover change using Landsat data, Remote Sens. Environ., Landsat Legacy Special Issue, 122, 66-74, 2012.

Hargreaves, G. H. and Samani, Z. A.: Reference Crop Evapotranspiration from Temperature, Appl. Eng. Agric., 1, 96-99, 1985.

Hastie, T. J. and Tibshirani, R. J.: Generalized Additive Models, CRC Press, Chapman and Hall/CRC Boca Raton, Florida, USA, 353 pp., 1990.

Held, I. M. and Soden, B. J.: Robust Responses of the Hydrological Cycle to Global Warming, J. Climate, 19, 5686-5699, 2006.

Heistermann, M., Müller, C., and Ronneberger, K.: Land in sight?: Achievements, deficits and potentials of continental to global scale land-use modeling, Agric. Ecosyst. Environ., 114, 141158, 2006.

Hijmans, R. J., Cameron, S. E., Parra, J. L., Jones, P. G., and Jarvis, A.: Very high resolution interpolated climate surfaces for global land areas, Int. J. Climatol., 25, 1965-1978, 2005.

Hijmans, R. J., Phillips, S., Leathwick, J., and Elith, J.: Species Distribution Modeling, 68 pp., Repository, CRAN, 9 January 2017.

Husak, G. J., Marshall, M. T., Michaelsen, J., Pedreros, D., Funk, C., and Galu, G.: Crop area estimation using high and medium resolution satellite imagery in areas with complex topography, J. Geophys. Res.-Atmos., 113, D14112, doi:10.1029/2007JD009175, 2008.

Jarvis, A., Reuter, H. I., Nelson, A., and Guevara, E.: Holefilled SRTM for the globe Version 4, CGIAR-CSI SRTM 90m Database, available at: http://www.cgiar-csi.org/data/ srtm-90m-digital-elevation (last access: 1 August 2015), 2008. 
Jayne, T. S. and Muyanga, M.: Land constraints in Kenya's densely populated rural areas: implications for food policy and institutional reform, Food Secur., 4, 399-421, 2012.

Jayne, T. S., Yamano, T., Weber, M. T., Tschirley, D., Benfica, R., Chapoto, A., and Zulu, B.: Smallholder income and land distribution in Africa: implications for poverty reduction strategies, Food Policy, 28, 253-275, 2003.

Kumar, S., Merwade, V., Rao, P. S. C., and Pijanowski, B. C.: Characterizing Long-Term Land Use/Cover Change in the United States from 1850-2000 Using a Nonlinear Bi-analytical Model, Ambio, 42, 285-297, 2013.

Lambin, E. F., Geist, H. J., and Lepers, E.: Dynamics of Land-Use and Land-Cover Change in Tropical Regions, Annu. Rev. Environ. Resour., 28, 205-241, 2003.

Lamprey, R. H.: Aerial Point Sampling (APS) Survey: Lake Basin, Machakos and Makueni, Kenya, 2012-13, Nairobi, Kenya, 2013.

Lawrence, P. J., Feddema, J. J., Bonan, G. B., Meehl, G. A., O’Neill, B. C., Oleson, K. W., Levis, S., Lawrence, D. M., Kluzek, E., Lindsay, K., and Thornton, P. E.: Simulating the Biogeochemical and Biogeophysical Impacts of Transient Land Cover Change and Wood Harvest in the Community Climate System Model (CCSM4) from 1850 to 2100, J. Climate, 25, 3071-3095, 2012.

Lepers, E., Lambin, E. F., Janetos, A. C., DeFries, R., Achard, F., Ramankutty, N., and Scholes, R. J.: A Synthesis of Information on Rapid Land-cover Change for the Period 1981-2000, BioScience, 55, 115-124, 2005.

MacDonald, A. M., Bonsor, H. C., Dochartaigh, B. É. Ó., and Taylor, R. G.: Quantitative maps of groundwater resources in Africa, Environ. Res. Lett., 7, 1-7, doi:10.1088/1748-9326/7/2/024009, 2012 (data available at: http://www.bgs.ac.uk/research/ groundwater/international/africanGroundwater/maps.html, last access: 23 July 2015).

Majale, M.: Employment creation through participatory urban planning and slum upgrading: The case of Kitale, Kenya. Habitat Int., Labour in Urban Areas, 32, 270-282, 2008.

Makarieva, A. M., Gorshkov, V. G., and Li, B.-L.: Revisiting forest impact on atmospheric water vapor transport and precipitation, Theor. Appl. Climatol., 111, 79-96, 2013.

Marshall, M. T., Husak, G. J., Michaelsen, J., Funk, C., Pedreros, D., and Adoum, A.: Testing a high-resolution satellite interpretation technique for crop area monitoring in developing countries, Int. J. Remote Sens., 32, 7997-8012, doi:10.1080/01431161.2010.532168, 2011.

Meiyappan, P., Dalton, M., O’Neill, B. C., and Jain, A. K.: Spatial modeling of agricultural land use change at global scale, Ecol. Model., 291, 152-174, 2014.

Moré, J. J.: The Levenberg-Marquardt algorithm: Implementation and theory, in: Numerical Analysis, Lecture Notes in Mathematics, edited by: Watson, G. A., Springer Berlin Heidelberg, 105116, 1978.

Ngetich, K. F., Mucheru-Muna, M., Mugwe, J. N., Shisanya, C. A., Diels, J., and Mugendi, D. N.: Length of growing season, rainfall temporal distribution, onset and cessation dates in the Kenyan highlands, Agric. For. Meteorol., 188, 24-32, 2014.

Norton-Griffiths, M.: Aerial Point Sampling for Land Use Surveys, J. Biogeogr., 15, 149-156, 1988.

Olofsson, P., Stehman, S. V., Woodcock, C. E., Sulla-Menashe, D., Sibley, A. M., Newell, J. D., Friedl, M. A., and Herold, M.: A global land-cover validation data set, part I: fundamental design principles, Int. J. Remote Sens., 33, 5768-5788, 2012.

Pengra, B., Long, J., Dahal, D., Stehman, S. V., and Loveland, T. R.: A global reference database from very high resolution commercial satellite data and methodology for application to Landsat derived $30 \mathrm{~m}$ continuous field tree cover data, Remote Sens. Environ., 165, 234-248, 2015.

Pielke, R. A., Pitman, A., Niyogi, D., Mahmood, R., McAlpine, C., Hossain, F., Goldewijk, K. K., Nair, U., Betts, R., Fall, S., Reichstein, M., Kabat, P., and de Noblet, N.: Land use/land cover changes and climate: modeling analysis and observational evidence, Wiley Interdiscip. Rev., Clim. Change, 2, 828-850, 2011.

Pinzon, J. E. and Tucker, C. J.: A Non-Stationary 1981-2012 AVHRR NDVI3g Time Series, Remote Sens., 6, 6929-6960, doi:10.3390/rs6086929, 2014 (data available at: https://ecocast. arc.nasa.gov/data/pub/gimms/, last access: 11 June 2015).

Pitman, A. J.: The evolution of, and revolution in, land surface schemes designed for climate models, Int. J. Climatol., 23, 479510, 2003.

Place, F.: Land Tenure and Agricultural Productivity in Africa: A Comparative Analysis of the Economics Literature and Recent Policy Strategies and Reforms, World Dev., The Limits of StateLed Land Reform, 37, 1326-1336, 2009.

Platts, P. J., Omeny, P. A., and Marchant, R.: AFRICLIM: highresolution climate projections for ecological applications in Africa, Afr. J. Ecol., 53, 103-108, doi:10.1111/aje.12180, 2014 (data available at: https://www.york.ac.uk/environment/research/ kite/resources/, last access: 18 June 2015).

Pongratz, J., Reick, C., Raddatz, T., and Claussen, M.: A reconstruction of global agricultural areas and land cover for the last millennium, Global Biogeochem. Cy., 22, GB3018, doi:10.1029/2007GB003153, 2008.

Pricope, N. G., Husak, G., Lopez-Carr, D., Funk, C., and Michaelsen, J.: The climate-population nexus in the East African Horn: Emerging degradation trends in rangeland and pastoral livelihood zones, Glob. Environ. Change, 23, 1525-1541, 2013.

Rindfuss, R. R., Walsh, S. J., Turner, B. L., Fox, J., and Mishra, V.: Developing a science of land change: Challenges and methodological issues, P. Natl. Acad. Sci. USA, 101, 13976-13981, 2004.

Rounsevell, M. D. A., Arneth, A., Alexander, P., Brown, D. G., de Noblet-Ducoudré, N., Ellis, E., Finnigan, J., Galvin, K., Grigg, N., Harman, I., Lennox, J., Magliocca, N., Parker, D., O’Neill, B. C., Verburg, P. H., and Young, O.: Towards decision-based global land use models for improved understanding of the Earth system, Earth Syst. Dynam., 5, 117-137, doi:10.5194/esd-5-1172014, 2014.

Schaldach, R. and Priess, J. A.: Integrated Models of the Land System: A Review of Modelling Approaches on the Regional to Global Scale, Living Rev. Landsc. Res., 2, 5-34, doi:10.12942/lrlr-2008-1, 2008.

Sheffield, J., Goteti, G., and Wood, E. F.: Development of a 50-Year High-Resolution Global Dataset of Meteorological Forcings for Land Surface Modeling, J. Climate, 19, 3088-3111, 2006.

Shevliakova, E., Pacala, S. W., Malyshev, S., Hurtt, G. C., Milly, P. C. D., Caspersen, J. P., Sentman, L. T., Fisk, J. P., Wirth, C., and Crevoisier, C.: Carbon cycling under 300 years of land use change: Importance of the secondary vegetation sink, Global 
Biogeochem. Cy., 23, GB2022, doi:10.1029/2007gb003176, 2009.

Sterling, S. M., Ducharne, A., and Polcher, J.: The impact of global land-cover change on the terrestrial water cycle, Nat. Clim. Change, 3, 385-390, 2013.

Tian, F., Fensholt, R., Verbesselt, J., Grogan, K., Horion, S., and Wang, Y.: Evaluating temporal consistency of long-term global NDVI datasets for trend analysis, Remote Sens. Environ., 163, 326-340, 2015.

Turner, B. L., Lambin, E. F., and Reenberg, A.: The emergence of land change science for global environmental change and sustainability, P. Natl. Acad. Sci. USA, 104, 20666-20671, 2007.

Turner, B. L., Janetos, A. C., Verbug, P. H., and Murray, A. T.: Land System Architecture: Using Land Systems to Adapt and Mitigate Global Environmental Change, Glob. Environ. Change, 232, 395-397, 2013.

UNEP/GRID: Sioux Falls, African Population Distribution Database (APDD), available at: http://na.unep.net/siouxfalls/ datasets/datalist.php (last access: 26 March 2015), 1987.

UNEP: Africa: Atlas of Our Changing Environment, UN Environment Programme, Nairobi, Kenya, 374 pp., 2008.

Vågen, T.-G., Winowiecki, L.A., Tondoh, J. E., Desta, L. T., and Gumbricht, T.: Mapping of soil properties and land degradation risk in Africa using MODIS reflectance, Geoderma, 263, 216$225,2016$. van Asselen, S. and Verburg, P. H.: Land cover change or landuse intensification: simulating land system change with a globalscale land change model, Global Change Biol., 19, 3648-3667, 2013.

Veldkamp, A. and Fresco, L. O.: CLUE-CR: An integrated multiscale model to simulate land use change scenarios in Costa Rica, Ecol. Model., 91, 231-248, 1996.

Verburg, P. H., Soepboer, W., Veldkamp, A., Limpiada, R., Espaldon, V., and Mastura, S. S. A.: Modeling the Spatial Dynamics of Regional Land Use: The CLUE-S Model, Environ. Manage., 30, 391-405, 2002.

Verburg, P. H., Neumann, K., and Nol, L.: Challenges in using land use and land cover data for global change studies, Glob. Change Biol., 17, 974-989, 2011.

Ward, D. S., Mahowald, N. M., and Kloster, S.: Potential climate forcing of land use and land cover change, Atmos. Chem. Phys., 14, 12701-12724, doi:10.5194/acp-14-12701-2014, 2014.

Wilson, T.: New Evaluations of Simple Models for Small Area Population Forecasts: Small Area Population Forecasts, Popul. Space Place, 21, 335-353, 2014. 